\title{
Social environment, behavior, and schistosomiasis in an urban population in the Northeast of Brazil
}

\author{
Ricardo Arraes de Alencar Ximenes, ${ }^{1}$ Brian Southgate, ${ }^{2}$ \\ Peter G. Smith, ${ }^{2}$ and Leonardo Guimaraes Neto ${ }^{3}$
}

ABSTRACT The objective of our study was to gain greater insight into the pattern of water contact in relation to schistosomiasis among residents of São Lourenço da Mata, a town in Pernambuco, a state in the Northeast of Brazil. We had two primary objectives: 1) to identify water contact activities that were more likely to produce infection and 2) to examine the socioeconomic factors behind water contact activities. Using a sample of persons 10-25 years old, we carried out a population-based case-control study to investigate the first objective, and a cross-sectional study for the second objective. We found that leisure water contact with flowing water (stream or river) was significantly associated with schistosomiasis. Variables showing a statistically significant association with leisure water contact were economic sector, income, and level of education of the head of the household; type of housing; possessions inside the house; type of domestic water supply; and method of excreta collection. We introduced these variables into a multivariate model to select the ones that were most closely associated with leisure water contact. We used a stepdown procedure, and two variables were retained in the final model: type of domestic water supply and type of housing. We concluded that a decrease in leisure water contact was associated with better socioeconomic conditions. Our results suggest that with the subjects we studied in São Lourenço da Mata there was a socioeconomic determination for leisure water contact. Our data highlight the importance of a broad and integrated approach in studying water contact activities and in implementing behavioral interventions for schistosomiasis prevention and control.

Key words Socioeconomic factors, schistosomiasis, water/parasitology.

There is much evidence that people's behavior affects agents, hosts, and the environment, and that behavior can also either increase or decrease the risk of a disease (1). Studying behavior may advance medical knowledge and increase the effectiveness of health protection and medical care.

\footnotetext{
Universidade Federal de Pernambuco, Departamento de Medicina Tropical, Recife, Pernambuco, Brazil. Send correspondence to: Ricardo Arraes de Alencar Ximenes, Universidade Federal de Pernambuco, Departamento de Medicina Tropical, Bloco A, Hospital das Clínicas, Universidade Federal de Pernambuco, Av. Moraes Rego s/n,
}

Cidade Universitária, Recife, Pernambuco, Brazil, CEP: 50670-420; telephone/fax: 55812718527.

2 University of London, London School of Hygiene and Tropical Medicine, Department of Infectious and Tropical Diseases, London, United Kingdom.

3 Universidade Federal da Paraíba, Departamento de Economia, João Pessoa, Paraíba, Brazil.
Health protection and medical care may in turn be bettered by influencing people to use available services and to change behaviors that are associated with an increase in the risk of a specific disease (2).

Behavioral research concerning schistosomiasis has progressed more than for any other major parasitic disease, with the possible exception of malaria (3). Behavioral studies on schistosomiasis have used different 
methods of collecting and analyzing data, and have been performed in various environments and time periods (4-15).

Studies of schistosomiasis and human water contact have two main purposes: 1) to describe and evaluate the contribution of such water contact to schistosomiasis transmission, and 2) based on the information about water contact patterns, to guide the choice of control measures, improve the implementation of existing measures, and evaluate the effectiveness of control programs (16).

The impact that health education has on people's attitudes and behavior may vary. Watts et al. (17) point out that water contact activities are processes taking place in a social, spatial, and temporal context, rather than a series of discrete activities performed by individuals. Macintyre (18) comments that attitudes, values, behavior, and lifestyle are not necessarily a result of the individual's choice; instead, they may be derived from social organization and the physical and social environments. Modifying attitudes and behavior may require social, economic, and political interventions.

Another important issue related to behavioral interventions is the extent to which methods of persuasion can be used while still respecting individual freedom of decision and choice (2).

We believe that water contact behavior may depend not only on the individual's own choice but also on constraints or opportunities generated by socioeconomic conditions. Therefore, our objective in this investigation was to create greater insight into the pattern of water contact in an urban population in the northeast of Brazil.

We tried, first, to identify the water contact activities that were most likely to produce infection and, second, to examine the socioeconomic factors behind the water contact activities. Our methodological approach to exploring that second objective differed from previous studies, in that we used the socioeconomic factors as independent variables and water contact as the outcome.

\section{METHODOLOGY}

We conducted our study in the urban section of the town of São Lourenço da Mata, in the state of Pernambuco, which is in the Northeast of Brazil. An estimated 50124 persons were living in the urban portion of the city in 1986 (19). São Lourenço da Mata is located some $20 \mathrm{~km}$ from the center of the city of Recife-the state capital of Pernambuco and one of the largest cities in Brazil-and thus can be considered part of the greater Recife metropolitan area.

São Lourenço da Mata has a natural stream system that feeds the Capibaribe River. There are streams and other bodies of water widely dispersed throughout the urban and rural sections of the town and the surrounding area. Schistosomiasis is endemic in the general area. The local intermediate host is Biomphalaria straminea, a snail that lives in a variety of habitats, including streams, ponds, ditches, and swamps.

\section{Study design and the sampling procedure}

The data we present in this paper are part of a broader project that had several objectives and was divided into three different parts. The first part of our research for this paper was a cross-sectional study in São Lourenço da Mata that had three goals: 1) to measure the prevalence of schistosomiasis among persons $10-25$ years old, 2) to estimate the socioeconomic characteristics of households with individuals aged 10-25 years, and 3) to investigate the association between the socioeconomic factors and schistosomiasis (20).

For the cross-sectional study, we selected 2864 building units, either family residential properties or other types of structures (Figure 1). We stratified the urban population of São Lourenço da Mata by area of residence, and we randomly selected a sample of households within each stratum (area), keeping the same sam- pling fraction for every stratum and thus ensuring the same proportion of houses for every area.

The list of building units that we used as our sample frame was provided by the local government's recorder of deeds office. Out of the 2864 units, 1825 of them had at least one resident aged 10 to 25 years old. In 775 households there was no one in that age group, and the number of nonresidential units (e.g., churches, schools, commercial establishments, and government buildings) was 264 . In those 1825 households, the total number of individuals in the age group of 10-25 years was 4329 , of whom 290 of them $(6.7 \%)$ refused the parasitological examination.

For the second part of our research, we used a population-based casecontrol design to investigate the association between the pattern of water contact and schistosomiasis. For the case-control investigation we included all cases among the persons aged 10-25 years old living in these 1825 households. According to estimates we had made based on the schistosomiasis prevalence found in previous studies and on 1980 census data for the town $(19,20)$, we had expected to find approximately 1166 schistosomiasis cases in this group of persons 10-25 years old in these 1825 households.

We used the same rationale to select a similar number of controls. We drew a subsample of 939 building units out of the whole sample of 2864 residential and nonresidential units. Again, we used stratified random sampling, with a uniform sampling fraction so that the total number of units in the subsample was allocated between the strata (areas) by proportionate allocation. Using the same estimating approach for the 939 units, we expected to find 4695 individuals, with 1548 of them in the age group of 10-25 years old. Out of the 1548 , we expected 382 of them to be positive for schistosomiasis, and the remaining 1166 would be in the control group.

To all the individuals in this age group with a parasitological examination that was positive for schistosomi- 
FIGURE 1. Sampling procedure for the three parts of the research on schistosomiasis, São Lourenço da Mata, Brazil, 1988

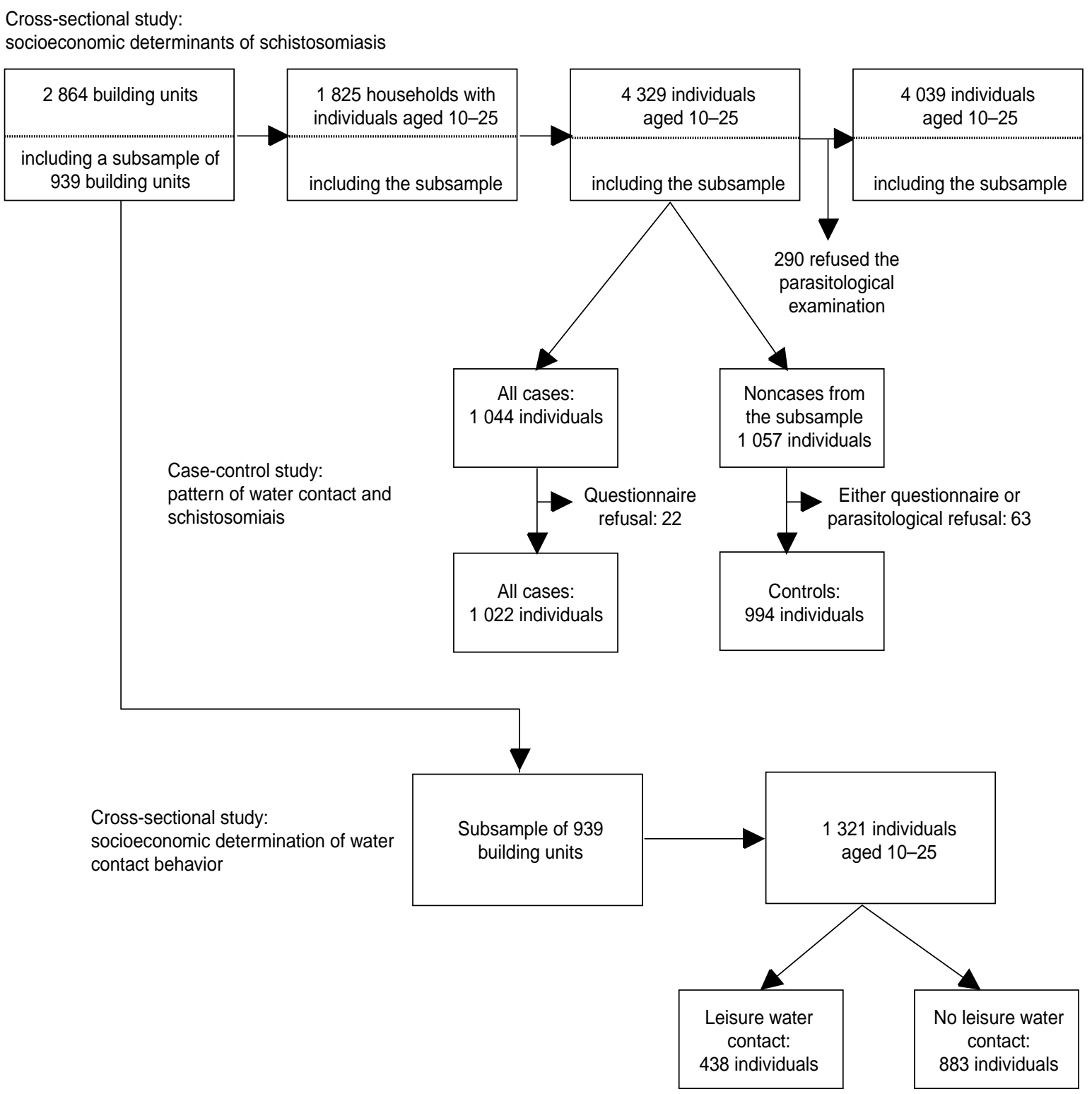

asis, as well as to the persons belonging to a subsample of those with a negative parasitological examination for schistosomiasis (i.e., the control group), we applied a questionnaire concerning type of water contact, migration history, and other characteristics. From another questionnaire, answered by the female head of the household, we obtained information on the socioeconomic characteristics of the head of the family and of the household. In this article we present information coming from the two questionnaires.

We attempted to apply questionnaires to a total of 2101 persons, 1044 cases and 1057 noncases (Figure 1). After excluding persons who declined to respond to the questionnaire or who refused the parasitological examination, we ended up with 2016 subjects,
1022 of them cases and 994 of them controls.

For the third part of our research, we conducted a second cross-sectional study, this one to investigate the socioeconomic factors behind leisure water contact. For this purpose we used socioeconomic factors as independent variables and leisure water contact as a binary outcome. From the case-control study we had information 
on the pattern of water contact of the cases and controls. However, in order to have a subsample that would be representative of the whole sample and of the entire population aged 1025 years, for this cross-sectional study we took just the individuals in this age group living in the 939 units drawn from the whole sample of 2864 building units. We took this approach in this third part of our research instead of selecting individuals according to their disease status (infected [cases] or not infected [controls]), which could have biased the association between the different exposures (socioeconomic variables) and the outcome (having had or not had a leisure water contact). From these 939 households we selected 1321 individuals, of whom 438 of them had had leisure water contact (Figure 1).

\section{Selection and definition of the variables}

We grouped water contact into five categories: fetching (for drinking or domestic use), professional, washing clothes, leisure, and fording. For our research, water contact meant contact with potential transmission sites, including still water (pond, lake, or dam), flowing water (stream or river), and a flowing water swimming pool (usually constructed in a stream bed, which does not receive any kind of treatment).

Under the heading of professional water contact we grouped such activities as irrigation, washing animals, and washing vehicles. As we thought that washing clothes could be a particularly important activity in the study area, we studied it separately. When we questioned individuals about their leisure water contact, we asked what they had done in the previous 4 weeks, and we used this as a proxy for the usual type of water contact.

Two other variables studied were the type of water body in which the water contact occurred and the place where the water contact took place (in urban or rural sections of São Lourenço da Mata or in other, nearby rural areas).
Leisure water contact is a broad term and different activities may be related to differences in the percent of the body surface exposed, in the duration of exposure, in the time of contact, etc. We examined whether there was any activity that was associated with a greater risk of infection.

Among the leisure water contact activities were bathing to cool off (often done in groups), washing the body (usually done alone), swimming (involving immersing the whole body), playing (often not immersing the entire body), and fishing. For those who reported leisure water contact with flowing water we also investigated if the distance of the water contact site from the person's residence and the frequency of exposure were associated with schistosomiasis. Distance was introduced as a three-level variable: a walk taking less than $10 \mathrm{~min}$, a walk taking more than $10 \mathrm{~min}$, or a distance that required transport (bicycle, car, bus, etc.) to cover. We sought a measure of the frequency of the water contact by defining contact as occurring several days a week, once a week, once or twice a month, or once every several months.

To study the association between water contact and socioeconomic conditions we used two groups of socioeconomic indicators: 1) variables that are more related to the place that the head of the family has in the productive process (income level and economic sector where employed) and 2) variables that are more connected with the pattern of consumption (level of education of the head of the household, type of housing, possessions inside the house, water supply for domestic use, and method of excreta collection). We considered the individuals in the age group of 10-25 years old as belonging to the same socioeconomic group as the head of the family. We believe that this assumption about belonging to the same socioeconomic group is true not only for those who are younger and/or dependent on the head of the family, but also for other individuals in the age group of 10-25 years who are earning a living, given that these individuals still live in the same house and share the same social environment as the head of the family.

\section{Data collection}

To conduct interviews using the two questionnaires - the one questionnaire for the female head of the household and the other questionnaire for the persons 10-25 years old-we selected four interviewers. These two males and two females resided in the area and were thus familiar with the social codes of the population. At the time of the interview neither the interviewers nor the women heads of the household nor the individuals in the age group of 10-25 years knew who was infected and who was not.

The interviewers also gave each household a labeled plastic container and a spatula to collect the material for the parasitological diagnosis of schistosomiasis from every individual in the family aged 10-25 years. Later, a specimen collector that we had hired picked up the material from each of the households. The fecal samples collected were transported at the end of each working day to a central laboratory, stored in a refrigerator, and then examined the following day.

For the diagnosis of schistosomiasis we employed the Kato method (21) as modified by Katz, Chaves, and Pellegrino (22). Two laboratory technicians performed the microscopic examination, and a third technician was responsible for preparing and allocating the slides to the technicians. As all the stool samples from one family were usually not received on the same day and as the allocation of slides per technician did not depend on the family they came from, the stool samples from different individuals in the same family were usually not read by the same technician. In addition, the two laboratory technicians knew nothing about the socioeconomic characteristics of the subjects for whom they were performing the parasitological examination

The data collection was done in 1988, over a period of 9 months. 
TABLE 1. Association of schistosomiasis with type of water contact and with gender, São Lourenço da Mata, Brazil, 1988a

\begin{tabular}{llcc}
\hline \multicolumn{1}{c}{ Variable } & $\begin{array}{c}\text { Odds } \\
\text { ratio }\end{array}$ & $\begin{array}{c}95 \% \text { confidence } \\
\text { interval }\end{array}$ & $\begin{array}{c}P \text { value } \\
\text { (two-sided) }\end{array}$ \\
\hline $\begin{array}{l}\text { Professional water contact } \\
\text { Has had }\end{array}$ & $1.00^{\mathrm{b}}$ & & \\
$\quad$ Has not had & 0.47 & $0.18-1.24$ & 0.12 \\
$\begin{array}{l}\text { Washing clothes water contact } \\
\quad \text { Has washed clothes }\end{array}$ & $1.00^{\mathrm{b}}$ & & 0.17 \\
$\quad$ Has not washed clothes & 0.64 & $0.33-1.22$ & \\
$\begin{array}{l}\text { Fording water contact } \\
\quad \text { Has had }\end{array}$ & $1.00^{\mathrm{b}}$ & & 0.63 \\
$\quad$ Has not had & 1.20 & $0.55-2.62$ & \\
$\begin{array}{l}\text { Leisure water contact } \\
\quad \text { Has had } \\
\quad \text { Has not had }\end{array}$ & $1.00^{\mathrm{b}}$ & & $<0.001$ \\
$\begin{array}{l}\text { Gender } \\
\text { Male }\end{array}$ & 0.44 & $0.37-0.54$ & $<0.001$ \\
$\quad$ Female & $1.00^{\mathrm{b}}$ & & \\
\hline
\end{tabular}

a Based on 2015 observations.

${ }^{\mathrm{b}}$ Reference.

${ }^{c}$ The variables of leisure water contact and gender were adjusted for each other.

\section{Data analysis}

We used logistic regression to investigate the relationship between schistosomiasis and age, sex, and pattern of water contact. For each independent variable (relating to the type of water contact, the site of the leisure water contact, or the type of leisure water contact activity) we estimated the odds ratio (OR), confidence interval (CI), and $P$ value. We also used the likelihood ratio test to test the hypothesis of no association between each variable and the disease.

We also employed a logistic model to test for an association between the socioeconomic variables and the pattern of water contact, using the former as the dependent variables and the latter as a binary outcome. We estimated the odds ratio associated with each level of each exposure relative to a baseline category, the confidence intervals, and significance ( $P$ value and likelihood ratio statistics). To model the joint effect of several exposures we adopted a stepdown procedure by introducing all the independent variables and dropping them one by one based on the likelihood ratio test statistics.

For basic data handling we used the SAS statistical package for data analy- sis (SAS Institute Inc., Cary, North Carolina, United States of America). To perform the logistic regression analysis we used a statistical package called GLIM (Generalised Linear Interactive Modelling) (Numerical Algorithms Group, Oxford, United Kingdom), which estimates the logistic parameters through a maximum likelihood approach.

\section{RESULTS}

\section{Pattern of water contact and schistosomiasis}

Concerning the type of water contact, none of the individuals questioned fetched water for drinking or for domestic use from still or flowing bodies of water.

Professional, washing clothes, and fording water contact were not significantly associated with schistosomiasis. There was evidence that those who did not have a leisure water contact were at a lower risk $(\mathrm{OR}=0.38,95 \%$ CI: $0.32-0.46, P<0.001)$. The risk was significantly reduced for females $(\mathrm{OR}=$ 0.44, 95\% CI: 0.37-0.53, $P<0.001)$. The association between schistosomiasis and leisure water contact was then reexamined, adjusting for gender (Table 1). After this adjustment the association of these two variables with schistosomiasis remained statistically significant.

We next examined the type of water body where leisure water contact occurred (Table 2). We found that such contact with flowing water (stream or river) was significantly associated with schistosomiasis. Persons who did not report leisure water contact with flowing water had a significantly lower risk of infection than those who reported such contact $(\mathrm{OR}=0.33,95 \%$ CI: $0.27-0.40, P<0.001)$.

Table 2 also shows the estimated odds ratios for the association of schistosomiasis and urban and rural water contact (adjusted for each other). Those who had never had a water contact in the urban sections of São Lourenço da Mata had one-third the risk. On the other hand, those who had never had a water contact in the rural sections of São Lourenço da Mata or other, nearby rural areas had a statistically significantly slightly lower risk of infection $(\mathrm{OR}=0.68,95 \%$ CI: 0.57-0.82, $P<0.001)$. Therefore, there is evidence that transmission is occurring in the urban sections of São Lourenço da Mata as well as in the rural areas of the town and nearby.

There were 664 individuals who reported leisure contact with flowing water. For this group of persons, swimming was the activity that was most strongly related to a risk of infection (Table 3). However, this does not indicate that such other activities as washing, bathing, playing, and fishing were not related to an increased risk of schistosomiasis.

Regarding the distance of the water contact site from the residence, there was a significant decrease in risk only for those needing transport to reach the water contact site $(\mathrm{OR}=0.36,95 \%$ CI: $0.17-0.77, P<0.01)$. Distance could be a proxy either for the frequency of the water contact or for the infectivity of the site.

Regarding the frequency of water contact, the odds ratios for the three other categories differed significantly from the baseline category of several 
TABLE 2. Association of schistosomiasis with site of leisure water contact, São Lourenço da Mata, Brazil, 1988

\begin{tabular}{|c|c|c|c|}
\hline Variable & $\begin{array}{l}\text { Odds } \\
\text { ratio }\end{array}$ & $\begin{array}{l}95 \% \text { confidence } \\
\text { interval }\end{array}$ & $\begin{array}{c}P \text { value } \\
\text { (two-sided) }\end{array}$ \\
\hline \multicolumn{4}{|l|}{ Contact with still water } \\
\hline Yes & $1.00^{\mathrm{b}}$ & & \\
\hline No & 0.78 & $0.56-1.08$ & 0.15 \\
\hline \multicolumn{4}{|c|}{ Contact with flowing water } \\
\hline Yes & $1.00^{\mathrm{b}}$ & & \\
\hline No & 0.33 & $0.27-0.40$ & $<0.001$ \\
\hline \multicolumn{4}{|c|}{$\begin{array}{l}\text { Contact with flowing water swimming } \\
\text { pool }\end{array}$} \\
\hline Has had & $1.00^{b}$ & & \\
\hline Has not had & 1.12 & $0.63-1.99$ & 0.72 \\
\hline \multicolumn{4}{|l|}{ Urban water contact $^{c}$} \\
\hline Ever had & $1.00^{\mathrm{b}}$ & & \\
\hline Never had & 0.33 & $0.28-0.41$ & $<0.001$ \\
\hline \multicolumn{4}{|l|}{ Rural water contact ${ }^{c}$} \\
\hline Ever had & $1.00^{\mathrm{b}}$ & & \\
\hline Never had & 0.68 & $0.57-0.82$ & $<0.001$ \\
\hline
\end{tabular}

days a week (data not shown). When distance of the water contact site from residence and the frequency of water contact were adjusted for each other, the odds ratio estimates for the different categories of frequency did not change appreciably. The adjusted

odds ratio for those who had water contact once a week was somewhat lower than for those who had water contact several days a week $(\mathrm{OR}=$ $0.64,95 \%$ CI: $0.42-0.97, P=0.04)$. The risk was only about half for those who had water contact once or twice a

TABLE 3. Association of schistosomiasis and leisure water contact activity, São Lourenço da Mata, Brazil, 1988a

\begin{tabular}{|c|c|c|c|}
\hline Variable & $\begin{array}{l}\text { Odds } \\
\text { ratio }\end{array}$ & $\begin{array}{c}95 \% \text { confidence } \\
\text { interval }\end{array}$ & $\begin{array}{c}P \text { value } \\
\text { (two-sided) }\end{array}$ \\
\hline \multicolumn{4}{|l|}{ Washing body } \\
\hline Has washed & $1.00^{\mathrm{b}}$ & & \\
\hline Has not washed & 1.40 & $0.89-2.19$ & 0.36 \\
\hline \multicolumn{4}{|l|}{ Bathing to cool off } \\
\hline Has done & $1.00^{b}$ & & \\
\hline Has not done & 0.78 & $0.45-1.34$ & 0.36 \\
\hline \multicolumn{4}{|l|}{ Playing } \\
\hline Has played & $1.00^{\mathrm{b}}$ & & \\
\hline Has not played & 0.69 & $0.47-1.02$ & 0.06 \\
\hline \multicolumn{4}{|l|}{ Swimming } \\
\hline Has swum & $1.00^{\mathrm{b}}$ & & \\
\hline Has not swum & 0.56 & $0.36-0.85$ & $<0.01$ \\
\hline \multicolumn{4}{|l|}{ Fishing } \\
\hline Has fished & $1.00^{b}$ & & \\
\hline Has not fished & 0.84 & $0.56-1.27$ & 0.41 \\
\hline \multicolumn{4}{|c|}{ Other type of leisure water activity } \\
\hline Has had & $1.00^{b}$ & & \\
\hline Has not had & 1.50 & $0.77-2.93$ & 0.23 \\
\hline
\end{tabular}

\footnotetext{
a Based on 659 observations for all of the variable categories except the last (658 observations).
}

${ }^{\mathrm{b}}$ Reference.

\section{Socioeconomic determination of leisure water contact}

To investigate the socioeconomic determinants of leisure water contact we used the socioeconomic factors as independent variables and leisure water contact as a binary outcome. Here, leisure water contact was taken independently of the site it took place (still water, flowing water, or flowing water swimming pool) and also independently of the area where it occurred (urban or rural). We took that approach because we had no reason to believe that the socioeconomic determinants of a leisure water contact would vary according to the site where it occurred.

Out of the 1321 individuals 10-25 years old whom we had selected in the third part of our research, 438 of them had had a leisure water contact. There were 670 males $(50.7 \%)$ and $651 \mathrm{fe}-$ males $(49.3 \%)$. In terms of age, 495 of them $(37.5 \%)$ were in the age group of $10-14$ years, $437(33.1 \%)$ in the age group of 15-19 years, and 389 (29.4\%) in the age group of 20-25 years.

We examined the association between socioeconomic factors and the risk of leisure water contact by persons 10-25 years old. None of the factors was expected to directly cause the outcome, but they were each an element in a complex set of social conditions implicated in the determination of the outcome.

We found a statistically significant association between leisure water contact and family income, with the two being inversely related (Table 4). The risk of leisure water contact for those individuals whose family had an income that was 5 or more times the minimum wage was less than a third 
TABLE 4. Association of leisure water contact with family income and with economic sector and level of education of the head of the household, São Lourenço da Mata, Brazil, 1988a

\begin{tabular}{|c|c|c|}
\hline Variable & $\begin{array}{l}\text { Odds } \\
\text { ratio }\end{array}$ & $\begin{array}{c}95 \% \text { confidence } \\
\text { interval }\end{array}$ \\
\hline \multicolumn{3}{|l|}{ Family income (multiple of minimum wage) } \\
\hline$<1$ & $1.00^{\mathrm{b}}$ & \\
\hline $1 \leq x<2$ & 0.58 & $0.41-0.82$ \\
\hline $2 \leq x<5$ & 0.43 & $0.29-0.65$ \\
\hline$\geq 5$ & 0.29 & $0.15-0.57$ \\
\hline \multicolumn{3}{|c|}{ Likelihood ratio statistic $=25.6$, degrees of freedom $=3, P<0.001$} \\
\hline \multicolumn{3}{|l|}{ Economic sector } \\
\hline Industry & $1.00^{\mathrm{b}}$ & \\
\hline Tertiary (commerce and services) & 0.62 & $0.46-0.84$ \\
\hline Farming, forestry, and fishing & 0.90 & $0.40-2.02$ \\
\hline Inactive and unemployed & 0.78 & $0.58-1.06$ \\
\hline \multicolumn{3}{|c|}{ Likelihood ratio statistic $=9.9$, degrees of freedom $=3, P=0.02$} \\
\hline \multicolumn{3}{|l|}{ Level of education } \\
\hline Illiterate & $1.00^{\mathrm{b}}$ & \\
\hline Literate but no formal level completed & 1.48 & $1.05-2.09$ \\
\hline "Primário" completed (4 yr of schooling) & 0.87 & $0.65-1.17$ \\
\hline "Ginásio" completed (8 yr of schooling) & 0.48 & $0.28-0.83$ \\
\hline "Secundário" completed (11 yr of schooling) & 0.39 & $0.21-0.74$ \\
\hline College completed & 1.63 & $0.54-4.94$ \\
\hline Likelihood ratio statistic $=28.9$, degrees of freed & & \\
\hline
\end{tabular}

that of the baseline level, for families whose income was less than 1 minimum wage.

We found a statistically significant association between leisure water contact by those 10-25 years old and the economic sector where the head of the household was employed (Table 4). We used a four-level variable for the economic sector: industry (manufacturing, utilities, construction, and mineral extraction); tertiary (commerce and services); farming, forestry, and fishing; and inactive and unemployed. There was evidence that the persons 10-25 years old in the households whose heads were employed in the tertiary sector were at a significantly lower risk of a leisure water contact than those whose heads were employed in industry.

The risk of those persons 10-25 years old having a leisure water contact varied according to the level of education of the head of the household (Table 4). That risk was significantly reduced where the head of the family had finished "ginásio" (8 years of formal
The type of water supply for domestic use was strongly associated with the risk of the subjects' leisure water contact (Table 5). The risk for those living in a house in which the water for domestic use came from a covered well, public standpipe, or piped water outside the house was one-fifth that of the subjects whose water supply was from a stream, river, or uncovered well. The risk for those with piped water inside the house was one-ninth that of the reference group.

We found a significant relation between leisure water contact and the method of excreta collection (Table 5).

We carried out a multivariate analysis to determine which of the seven categories of socioeconomic variables were most closely related to leisure water contact. After applying a stepdown procedure, two variables were retained in the final model: water supply and of type of housing.

The area of residence within São Lourenço da Mata, sex, and age group were potential confounders of the association with the socioeconomic variables. To make allowance for the effects of area of residence, sex, and age group, they were then included in the final model (Table 6) (data on area of residence not shown).

When area of residence, sex, and age group were introduced into the final model, the association between leisure water contact and the socioeconomic variables of water supply and type of housing remained statistically significant. On the other hand, the association of leisure water contact with sex, age group, and area of residence was still significant when adjusted for each other and for the socioeconomic variables.

\section{DISCUSSION}

walls made of redbrick and a floor of tile, marble, or similar material.

As Table 5 also shows, there was a statistically significant association between the subjects' leisure water contact and having such possessions inside the house as a refrigerator, TV set, gas stove, bicycle, stereo set, telephone, and air conditioning.

\section{Pattern of water contact and schistosomiasis}

We found that leisure water contact was the only type of water contact significantly associated with schistosomiasis. Other researchers (6) found similar results with a cross-sectional study 
TABLE 5. Association of leisure water contact and type of housing, possessions inside the house, domestic water supply, and method of excreta collection, São Lourenço da Mata, Brazil, 1988

\begin{tabular}{|c|c|c|}
\hline Variable & $\begin{array}{l}\text { Odds } \\
\text { ratio }\end{array}$ & $\begin{array}{l}95 \% \text { confidence } \\
\text { interval }\end{array}$ \\
\hline \multicolumn{3}{|l|}{ Type of housing } \\
\hline Type I (slum) & $1.00^{\mathrm{b}}$ & \\
\hline Type II (mud, redbrick; cement or dirt floor) & 0.36 & $0.21-0.62$ \\
\hline Type III (redbrick; cement floor) & 0.22 & $0.16-0.30$ \\
\hline Type IV (redbrick; floor of tile, marble, etc) & 0.16 & $0.10-0.25$ \\
\hline \multicolumn{3}{|c|}{ Likelihood ratio statistic $=104.1$, degrees of freedom $=3, P<0.001$} \\
\hline \multicolumn{3}{|l|}{ Possessions inside the house } \\
\hline Category I (no refrigerator, TV set, or gas stove) & $1.00^{\mathrm{b}}$ & \\
\hline Category II (refrigerator and/or TV set and/or gas stove) & 0.52 & $0.31-0.86$ \\
\hline $\begin{array}{l}\text { Category III (sewing machine and/or bicycle and/or fan } \\
\text { and/or stereo set) }\end{array}$ & 0.35 & $0.22-0.57$ \\
\hline $\begin{array}{l}\text { Category IV (telephone and/or motorbike and/or car } \\
\text { and/or air conditioning) }\end{array}$ & 0.32 & $0.18-0.60$ \\
\hline Likelihood ratio statistic $=24.6$, degrees of freedom $=3, P$ & & \\
\hline \multicolumn{3}{|l|}{ Water supply } \\
\hline Category I (stream, river, or uncovered well) & $1.00^{b}$ & \\
\hline Category II (covered well, public standpipe, or piped & & \\
\hline water but not inside the house) & 0.20 & $0.13-0.30$ \\
\hline Category III (piped water inside the house) & 0.11 & $0.07-0.17$ \\
\hline \multicolumn{3}{|c|}{ Likelihood ratio statistic $=107.8$, degrees of freedom $=2, P<0.001$} \\
\hline \multicolumn{3}{|l|}{ Excreta collection } \\
\hline Level I (no sanitary facility) & $1.00^{\mathrm{b}}$ & \\
\hline $\begin{array}{l}\text { Level II (sanitary facility but excreta conveyed to either } \\
\text { still or flowing water) }\end{array}$ & 0.49 & $0.22-1.07$ \\
\hline Level III (excreta conveyed to pit or tank) & 0.43 & $0.25-0.74$ \\
\hline Level IV (connection with the city sewage system) & 0.25 & $0.14-0.46$ \\
\hline Likelihood ratio statistic $=25.5$, degrees of freedom $=3, P$ & & \\
\hline
\end{tabular}

done in a suburban area of Belo Horizonte, a large industrial city in Brazil. However, this is not the most common pattern that other studies have found in small villages and rural areas (14).

We found that swimming was the activity most related to a risk of infection; this is not surprising since this activity exposes the whole surface of the body to the water. This same result has been found in other studies $(6,23)$.

We found that frequency of contact was related to the risk of the infection, but distance between the individual's home and the water contact site did not seem to play an important role. This can be easily explained by the large number of water bodies that offer opportunities for water contact within the urban area and rural areas of São Lourenço da Mata and nearby. Other studies have reached differing conclusions concerning frequency and distance $(7,9,24)$. These various studies all provide useful information, but for the planning of local interventions they should be supplemented by broader research.

\section{Socioeconomic determination of leisure water contact}

A decrease in leisure water contact was associated with better socioeconomic conditions. In other words, regardless of individual variability, our results suggest that in São Lourenço da Mata there is socioeconomic determination of leisure water contact in subjects aged $10-25$ years.

There was a large decrease in the risk of leisure water contact for those subjects aged 10-25 years old who had piped water inside the house. This fact highlights the importance of providing an adequate water supply directly to individuals' homes in order to reduce water contact with potential transmission sites. Even when the category of water supply was adjusted for the effect of the type of housing, there was still a substantial decrease in risk for persons with piped water inside the house.

In tropical areas such as the one we studied, young persons perform much physical activity, both when playing games and when working. There is no doubt that for these young subjects contact with still or flowing water is pleasurable. Therefore, for their water contact it may not be easy to establish the boundary between leisure and needs. Leisure itself is a need, and the life of many poor persons in São Lourenço da Mata may not offer many opportunities for recreation. Further, because of the absence of piped water inside the house, water contact elsewhere may be a more convenient and agreeable way of meeting the needs of self-hygiene and of cooling down on a hot day.

Since school attendance is not compulsory in Brazil, poorer individuals are more likely to be out of school, to be moving around freely from an early age, and to be engaged in jobs requiring physical effort. All these factors may combine to increase the opportunities for water contact, as well as the need for it. Thus, a wide spectrum of social phenomena may lie behind a specific behavior. The results that we found from our focus on socioeconomic conditions lend support to the idea that attempts to influence people to change their behavior may fail if the social context in which these individuals make choices is ignored. Instead, there is a need to understand the interaction between behavior and socioeconomics, and to integrate the two. 
TABLE 6. Association of leisure water contact with socioeconomic variables (adjusted for each other) and for area of residence, sex, and age group, São Lourenço da Mata, Brazil, $1988^{\mathrm{a}, \mathrm{b}}$

\begin{tabular}{|c|c|c|c|}
\hline Variable & $\begin{array}{l}\text { Odds } \\
\text { ratio }\end{array}$ & $\begin{array}{l}95 \% \text { confidence } \\
\text { interval }\end{array}$ & $\begin{array}{c}P \text { value } \\
\text { (two-sided) }\end{array}$ \\
\hline \multicolumn{4}{|l|}{ Water supplyc } \\
\hline Category I & $1.00^{d}$ & & \\
\hline Category II & 0.28 & $0.16-0.49$ & $<0.001$ \\
\hline Category III & 0.22 & $0.11-0.41$ & $<0.001$ \\
\hline \multicolumn{4}{|l|}{ Type of housing ${ }^{C}$} \\
\hline Category I & $1.00^{d}$ & & \\
\hline Category II & 0.45 & $0.24-0.86$ & $<0.02$ \\
\hline Category III & 0.44 & $0.28-0.69$ & $<0.01$ \\
\hline Category IV & 0.19 & $0.10-0.36$ & $<0.001$ \\
\hline \multicolumn{4}{|l|}{ Age group } \\
\hline $10-14$ years & $1.00^{d}$ & & \\
\hline $15-19$ years & 0.97 & $0.71-1.32$ & 0.98 \\
\hline 20-25 years & 0.49 & $0.35-0.69$ & $<0.001$ \\
\hline \multicolumn{4}{|l|}{ Sex } \\
\hline Male & $1.00^{d}$ & & \\
\hline Female & 0.21 & $0.16-0.28$ & $<0.001$ \\
\hline
\end{tabular}

a The data on area of residence is not shown.

b Based on 1318 observations.

${ }^{c}$ Descriptions of the water supply and housing categories are included in Table 5.

d Reference.

Only $49.6 \%$ of the families we sampled had piped water inside the house (20). A scarcity of water resources is certainly not the explanation for this low figure, given that one of the dams that supplies water for the whole metropolitan region of Recife is located in São Lourenço da Mata. Part of the explanation may come from looking at the data we gathered on water supply and family income. We found that only $33 \%$ of the families receiving less than 2 minimum wages had a piped water supply inside the house, while the fig- ure was $73.8 \%$ for families receiving 2 or more minimum wages (20). Nevertheless, any attempts to establish a more universal distribution of piped water as part of a schistosomiasis control program, as well as provision of sanitation and wider aspects of development that may affect the prevalence of infection, may go against other interests of the local or national government or other dominant groups with other priorities for public expenditures.

Our findings support the views of Crawford (25), who suggested the need to question the ideology of individual responsibility. That ideology puts forth a concept of wise living that considers individuals to be essentially independent of their surroundings and unconstrained by social events and processes. Even when pressures on individuals are recognized, it is still the individuals who are called upon to resist them. On the other hand, it is important to avoid a deterministic view, which argues that individuals have no choice.

In two other papers $(26,27)$ we have discussed other issues related to schistosomiasis and social context, including migration and socioeconomic determinants. Our data in this paper and those two other papers highlight the importance of a broad and integrated approach to studying water contact activities and to implementing behavioral interventions for schistosomiasis prevention and control. Such an approach should incorporate the intersection of such key issues in human behavior as gender, space, time, work, and social inequalities.

Acknowledgments. This investigation received financial support from the UNDP/World Bank/WHO Special Programme for Research and Training in Tropical Diseases (TDR). Ricardo Ximenes gratefully acknowledges a grant from the Conselho Nacional de Desenvolvimento Cientifico e Tecnológico of Brazil.

\section{REFERENCES}

1. Heggenhougen HK, Shore L. Cultural components of behavioural epidemiology: implications for primary health care. Soc Sci Med 1986;22(11):1235-1245.

2. Baric L, Ed. Behavioural sciences in health and disease. Geneva: International Journal of Health Education; 1972.

3. Dunn FF. Behavioural aspects of the control of parasitic diseases. Bull World Health Organ 1979;57(4):499-512.

4. Chandiwana SK. Seasonal patterns in water contact and the influence of water availability on contact activities in two schistosomiasis endemic areas in Zimbabwe. Cent Afr J Med 1987;33(1):8-15.

5. Cetron MS, Chitsulo L, Sullivan JJ, Pilcher J, Wilson M, Noh J, et al. Schistosomiasis in Lake Malawi. Lancet 1996;348(9037):1274-1278.

6. Firmo JO, Lima Costa MF, Guerra HL, Rocha RS. Urban schistosomiasis: morbidity, sociodemographic characteristics and water contact patterns predictive of infection. Int J Epidemiol 1996;25(6):1292-1300.

7. Fulford $\mathrm{AJ}$, Ouma JH, Kariuki HC, Thiongo FW, Klumpp R, Kloos H, et al. Water contact observations in Kenyan communities en- demic for schistosomiasis: methodology and patterns of behaviour. Parasitology 1996; 113(3):223-241.

8. el Kholy H, Arap Siongok TK, Koech D, Sturrock $\mathrm{RF}$, Houser $\mathrm{H}$, King $\mathrm{CH}$, et al. Effects of borehole wells on water utilization in Schistosoma haematobium endemic communities in Coast Province, Kenya. Am J Trop Med Hyg 1989;41(2):212-219.

9. Kloos H, Fulford AJ, Butterworth AE, Sturrock RF, Ouma JH, Kariuki HC, et al. Spatial patterns of human water contact and Schistosoma mansoni transmission and infection in 
four rural areas in Machakos District, Kenya. Soc Sci Med 1997;44(7):949-968.

10. Klumpp RK, Webbe G. Focal, seasonal and behavioural patterns of infection and transmission of Schistosoma haematobium in a farming village at the Volta Lake, Ghana. J Trop Med Hyg 1987;90(5):265-281.

11. Kvalsvig JD, Becker PJ. Selective exposure of active and social children to schistosomiasis. Ann Trop Med Parasitol 1988;82(5):471-474.

12. Kvalsvig JD, Schutte $\mathrm{CH}$. The role of human water contact patterns in the transmission of schistosomiasis in an informal settlement near a major industrial area. Ann Trop Med Parasitol 1986;80(1):13-26.

13. Mota E, Sleigh AC. Water-contact patterns and Schistosoma mansoni infection in a rural community in northeast Brazil. Rev Inst Med Trop Sao Paulo 1987;29(1):1-8.

14. Tiglao TV, Camacho AC. Water contact behaviour among humans in Leyte, Philippines. Southeast Asian J Trop Med Public Health 1983;14(1):18-24.

15. Woolhouse ME. Mathematical models of transmission dynamics and control of schistosomiasis. Am J Trop Med Hyg 1996;55(5 Suppl):144-148.

16. World Health Organisation. Workshop on the role of human/water contact in schistosomiasis transmission, St. Lucia, 28 May-1 June
1979. Geneva: WHO; 1979. (Document TDR/ SER-HWC/79.3)

17. Watts S, Klallaayoune K, Bensefia R, Laamrani $\mathrm{H}$, Gryseels B. The study of human behaviour and schistosomiasis transmission in an irrigated area in Morocco. Soc Sci Med 1998;46(6):755-765.

18. Macintyre $S$. The patterning of health by social position in contemporary Britain - direction for sociological research. Soc Sci Med 1986;23(4):393-415.

19. FIDEM-Fundação de Desenvolvimento da Região Metropolitana do Recife, Fundação de Informações para o Desenvolvimento de Pernambuco-FIDEPE, Secretaria de Planejamento. São Lourenço da Mata. Informações municipais. Recife: Recife Gráfica Editora Ltda.; 1982.

20. Ximenes RAA. Urbanization of schistosomiasis - Metropolitan Region of Recife. (Social causation of schistosomiasis in the age-group 10-25 years in the urban area of the "distrito" of São Lourenço da Mata) [PhD dissertation]. London, United Kingdom: London School of Tropical Medicine and Hygiene, University of London; 1991

21. Kato K, Miura M. Comparative examinations. Japanese Journal of Parasitology 1954;3:35.

22. Katz N, Chaves A, Pellegrino J. A simple device for quantitative stool thick-smear tech- nique in Schistosomiasis mansoni. Rev Inst Med Trop Sao Paulo 1972;14(6):397-400.

23. Amorim MN, Rabello A, Contreras RL, Katz N. Epidemiological characteristics of Schistosoma mansoni infection in rural and urban endemic areas of Minas Gerais, Brazil. Mem Inst Oswaldo Cruz 1997;92(5):577-580.

24. Akogun OB, Akogun MK. Human behaviour, water usage and schistosomiasis transmission in a small settlement near Yola, Nigeria. Ann Trop Med Parasitol 1996;90(3):303-311.

25. Crawford R. You are dangerous to your health: the ideology and politics of victim blaming. Int J Health Serv 1977;7(4):663-680.

26. Ximenes R, Smith P, Southgate B. Migration and urban schistosomiasis - the case of São Lourenço da Mata, Northeast of Brazil. Rev Inst Med Trop São Paulo 2000;42(4):209-217.

27. Ximenes R, Smith P, Southgate B. Socioeconomic determination of schistosomiasis in an urban area in São Lourenço da Mata, Northeast of Brazil. Submitted for publication.

Manuscript received 27 December 1999. Revised version accepted for publication on 21 October 2000.

RESUMEN El objetivo de este estudio consistió en contribuir a una mejor comprensión de la relación entre el tipo de contacto con el agua y la esquistosomiasis en los residentes de São Lourenço da Mata, una ciudad del estado de Pernambuco, en el Nordeste de Brasil. Los dos objetivos principales fueron: 1) identificar los tipos de contacto con el agua con mayores probabilidades de producir infección, y 2) investigar los factores socioeconómicos subyacentes a esas actividades. Utilizando una muestra de personas de 10 a 25 años de edad, se realizó un estudio de casos y controles basado en la población para alcanzar el primer objetivo, y un estudio transversal para el segundo objetivo. Se comprobó que las actividades recreativas que implicaban contacto con cursos de agua (arroyos o ríos) estaban significativamente asociadas a la esquistosomiasis; las variables asociadas de forma significativa con dichas actividades fueron el sector económico, los ingresos y el nivel de educación del cabeza de familia; el tipo de domicilio y los enseres que contenía; el tipo de suministro de agua al domicilio, y el sistema de eliminación de los excrementos. Estas variables fueron introducidas de forma escalonada en un modelo multivariado para seleccionar las más estrechamente asociadas al contacto recreativo con el agua. En el modelo final quedaron dos variables: el tipo de suministro de agua al domicilio y el tipo de domicilio. Se concluyó que el menor contacto recreativo con el agua estaba asociado a mejores condiciones socioeconómicas. Los resultados obtenidos indican que, en los sujetos estudiados de São Lourenço da Mata, el contacto recreativo con el agua era determinado por factores socioeconómicos y destacan la importancia de un abordaje amplio e integrado a la hora de estudiar las actividades que implican contacto con el agua y de poner en práctica intervenciones conductuales de prevención y control de la esquistosomiasis. 